\title{
La adquisición de la competencia narrativa a través del cómic en la Escuela Primaria
}

\section{The acquisition of narrative competence through comics in Primary School}

\author{
Blas SEGOVIA AGUILAR \\ Universidad de Córdoba
}

Recibido: Febrero 2012

Aceptado: Marzo 2012

\section{Resumen}

En el presente artículo describimos una serie de aspectos que favorecen el desarrollo de la competencia narrativa de los niños y cómo ésta se adquiere mediante el cómic.

El cómic destaca por su versatilidad entre los diversos medios de comunicación que permiten la creación de narraciones con imágenes en la infancia, pues su material expresivo se basa en el dibujo y la escritura sin necesidad de acudir a instrumentos tecnológicos sofisticados para la producción del discurso.

El análisis de los factores psicolingüísticos que intervienen en el acto narrativo nos permite esbozar una metodología eficaz para abordar un aspecto esencial de la educación mediática: aprender a narrar con imágenes.

Para narrar con imágenes, el niño necesita saber cómo construir la estructura temporal del relato y como trasladar el argumento al lenguaje del cómic.

En este trabajo, proponemos directrices para la integración de este recurso didáctico en diferentes áreas del curriculum en la escuela primaria.

Palabras clave: narrativa visual, competencia narrativa, cómic en la infancia, alfabetización mediática, educación mediática, comunicación y educación.

\begin{abstract}
In this paper we describe a range of aspects that favor the development of narrative competence of children, and how it is acquired through comics.

Comics are well known for its versatility among the various media that allow the creation of stories with images in children, as its expressive material is based on drawing and writing without the need to resort to sophisticated technological tools for the production of speech.

The analysis of psycholinguistic factors involved in the narrative act allows us to sketch an effective methodology to address an essential aspect of media education: learning to tell stories with pictures. To narrate with images, the child needs to know how to construct the term structure of the story and how to translate the argument into the language of comics.

We propose guidelines for the integration of this resource didactic in different areas of the curriculum in elementary school.
\end{abstract}

Keywords: visual storytelling, narrative competence, comics in childhood, media literacy, media education, communication and education. 
La narración es, según Jerome Bruner (2006) "la forma de expresión que mejor comprende el niño, quizá por ser el modo habitual y más propio de la cultura popular, pues la narración es un tipo de expresión que simplifica la comprensión de la realidad, permitiendo hacer que lo excepcional se convierta en comprensible". Esta potencialidad respecto a otras formas expresivas, refuerzan el valor de lo narrativo como herramienta fundamental para una adecuada alfabetización letrada, audiovisual o mediática centrada en la comunicación.

Mediante la narración el niño interpreta la realidad social, navegando en mundos imaginarios de la mano del lenguaje, pero los procesos cognitivos y los aprendizajes necesarios que permiten la elaboración de las historias son, al tiempo, complejos, por lo que requieren de un tratamiento pedagógico singular a lo largo de los primeros años de la escolaridad. Este acceso a la narración en el contexto escolar, desde la perspectiva expuesta, requiere la necesidad de la contextualización y la preponderancia de la situación comunicativa como ejes de la actividad, e implica que aprender a escribir (con el lenguaje que sea) es también aprender a usar la lengua de forma adecuada a la situación y al contexto, por lo que estos aprendizajes no pueden desarrollarse con el estudio de formas lingüísticas alejadas de su uso en los contextos reales de producción.

Al mismo tiempo, la narración posibilita el acceso a la cultura, ya que es un instrumento mediante el que niños y adultos construyen los procesos de socialización, tanto en el entorno familiar como en el escolar, pues es consecuencia de un modo de construir significados, un modo de pensamiento. Como exponen Santamaría y Martínez (2005: 173) "la psicología narrativa va a concebir a la narración como una acción eminentemente social y discursiva, como algo más que un conjunto de géneros literarios o una categoría particular de habla. Más bien será un modo básico, quizá el más básico, de comprensión humana, el procedimiento por el que los individuos organizan su experiencia en las transacciones con el mundo social".

Las narraciones desempeñan, por tanto, un importante papel en el acceso de los niños a la cultura popular, principalmente a través de viejas y nuevas formas narrativas como los cuentos populares, las historietas, las películas, los dibujos animados y las series de televisión. En todas ellas, se desarrollan historias que presentan diversas modalidades narrativas caracterizadas por un factor común: se sustentan en un modo de presentar y comprender la ficción utilizando estrategias cognitivas propias de una particular forma de pensamiento: el narrativo (Bruner, 2004; Mateos Blanco y Núñez Cubero, 2011; Smorti, 2001; Santamaría y Ramírez, 1998), que se encuentra relacionado con procesos cognitivos peculiares, encaminados a la creación de significados, siguiendo esquemas de pensamiento diferentes a los que se producen cuando se utilizan otras modalidades de pensamiento como el argumentativo.

El concepto de competencia es, sin duda, uno de los que más atención están requiriendo desde las ciencias de la educación en los últimos años. Entendemos la competencia como un conjunto de conocimientos, capacidades y actitudes que permiten aplicar los saberes en contextos diversos. Aunque en la cultura occidental los contextos se encuentran mediados por modelos comunicativos basados en la imagen, el desarrollo de aprendizajes destinados a la consecución de una adecuada educación en 
comunicación audiovisual, tal y como reconoce Joan Ferrés (2007), se encuentra excluida de los currículos educativos. No obstante, la definición de los ámbitos en los que se debe de sustentar dicho espacio curricular están ampliamente consensuados por expertos educomunicadores españoles e iberoamericanos (Ferrés, 2007) y en los modelos de alfabetización mediática procedentes del mundo anglosajón (Gutiérrez y Tyner, 2012; Lankshear y Knobel, 2008; Lonsdale y McCurry, 2004).

En todas estas propuestas se defiende la importancia de adquirir habilidades para profundizar en el ámbito de la expresión con lenguajes icónicos para poder elaborar textos audio o escritovisuales y, desde nuestra perspectiva, estás habilidades dependen en gran medida de la adquisición de la competencia narrativa, necesaria para la adecuada construcción del discurso narrativo.

\section{Narrar con imágenes en la infancia}

Los estudios realizados para la comprensión del desarrollo de la narración en la infancia se han realizado desde diferentes enfoques.

Durante la última década del pasado siglo, destacaron los estudios centrados en el texto, vinculados con las teorías del procesamiento de la información. Éstos fijaron su atención en conocer cómo la gramática implícita en todo texto es asimilada por el sujeto, o dicho de otro modo, cómo el sujeto impone al texto una gramática mental propia. En esta línea se inscriben las investigaciones sobre las gramáticas de las historias (Gárate, 1994; Mandler y Jhonson, 1977; Rumerhart, 1975; Stein y Glenn ,1982; o Thorndyke,1977) que plantean un paralelismo entre la estructura textual de la narración y la gramática mental subyacente a la comprensión o producción de las narraciones por parte de los niños.

Paralelamente, los trabajos de autores como Bruner (1986, 1990); Gergen (1994); Murray (1995); Sarbin (1986); Smorti (2001), permiten hablar de una psicología narrativa que difiere en sus planteamientos de la narratología o de la teoría literaria para centrarse en el individuo, teniendo presente la dimensión contextual. Smorti (2001: 67) plantea que "esta perspectiva enlaza con la tradición hermenéutica, que hace del análisis del relato el resultado de un trabajo de interpretación en el que el texto y contexto presentan una relación circular".

Ambos enfoques son importantes para el estudio de las narrativas infantiles y suponen tener en cuenta tanto los aspectos cognitivos como los aspectos de carácter interactivo o social. En este sentido, hemos de considerar que construir narraciones constituye una tarea cognitiva en la que se conjugan diversos tipos de conocimientos, unos dependientes de la capacidad para realizar operaciones cognitivas utilizando el pensamiento narrativo y otras derivadas de las habilidades y competencias lingüísticas adquiridas. Además, interviene la gestión que el individuo hace de su historiografía personal, construida a partir de las interacciones mantenidas con la colectividad.

Producir narraciones, tal y como sugiere White (1980) puede considerarse como la solución a un problema de carácter general: el problema de traducir el saber en decir. 
Por ello, es importante, especialmente desde el ámbito de la educación, conocer qué saberes son necesarios para construir narrativas con eficacia, y éstos habrán de atender a las dos dimensiones presentes en cualquier narración: la del relato y la del discurso.

El escolar, cuando produce narraciones, ha de combinar conocimientos relativos a la estructura del relato que desea elaborar junto con otros encargados de la elaboración del discurso. Al tiempo ha de dominar tres niveles de elaboración textual: el de la acción lingüística general -responsable del sentido de la comunicación-, el de la producción textual -necesario para la adecuación formal del texto- y el de la contextualización -vinculado con los géneros discursivos y la dimensión pragmática del discurso-.

En consecuencia, para el desarrollo de la narrativa visual en la infancia distinguiremos, cuatro tipos de conocimientos relacionados con: el contenido, la estructura, los aspectos lingüísticos y los contextuales.

\section{Conocimientos relacionados con el dominio del contenido}

El contenido de la historia es una dimensión dependiente del plano del relato, y está constituido por una serie de representaciones de eventos generales y sucesos específicos organizados en función de dos estructuras: la argumental y la de los elementos dramáticos. La primera organiza los objetos y las acciones sobre un eje espacio-temporal, mientras que la segunda establece relaciones de manera coherente entre los personajes, las acciones, las motivaciones, los escenarios, así como los problemas generadores de la acción. De esta segunda estructura depende la coherencia interna del relato.

El escolar, para poder elaborar el contenido de una narración oral, escrita, gráfica o audiovisual, ha de ser capaz de actualizar, mediante la memoria, el conocimiento que posee de un determinado evento, y organizarlo en función del modelo de narrativa que pretende construir.

Dependiendo de la complejidad del contenido, el argumento puede estar referido a un evento personal o a una historia de ficción. En el primer caso él es el protagonista y los hechos suelen rememorar situaciones vividas, por lo que se adecuan mejor a los primeros años de la escolaridad, mientras que en las historias de ficción aumenta la complejidad, ya que el autor ha de organizar un argumento en el que participan personajes de ficción que se proponen metas en diversos escenarios, ha de organizar la trama en la que pueden aparecer variadas acciones de manera secuenciada en un eje temporal y ha de dar una visión general de lo que sucede en la historia. En consecuencia, algunas de las habilidades narrativas indispensables para la elaboración del contenido tienen como finalidad la plasmación completa del suceso en el argumento, la secuencia ordenada de las acciones, la identificación clara de los personajes con sus relaciones y la definición del problema que genera la acción dramática. 
Para favorecer la adquisición de conocimientos que repercutan en el desarrollo de la competencia narrativa en relación con el contenido del relato, es necesario incluir actividades desde los primeros cursos de la educación primaria utilizando el lenguaje oral o el dibujo para identificar claramente a los personajes, describiendo sus principales características y exponiendo sucesos y acciones en una sencilla estructura temporal. Las historias que más fácilmente puede elaborar el niño de estas edades son las relativas a eventos personales o sucesos que le han ocurrido en su entorno social cercano: viajes con la familia, acciones propias del pasado cercano, etc. En todas ellas conviene insistir con el rigor necesario para identificar a los personajes y los hechos, ordenándolos cronológicamente para acostumbrarlos a que la trama descanse en una determinada estructura temporal. Desde nuestra óptica, paralelamente se debe de seguir trabajando con los formatos propios de la narrativa infantil, como los cuentos populares o relatos adecuados de la literatura infantil.

De igual modo, en la medida que nos situamos en cursos de $3^{\circ}$ y $4^{\circ}$ de primaria, el profesorado debe introducir modelos narrativos que admiten una mayor complejidad estructural como son los relatos de ficción. Estos nos permiten centrar la atención en las unidades básicas de la acción administrando adecuadamente a los personajes y los sucesos en el espacio y tiempo. En estas edades, en las que el escolar ya ha adquirido los rudimentos básicos para la expresión escrita, junto con la oralidad se debe compaginar la expresión escrita y, en nuestro caso, la elaboración de historietas de una página con seis viñetas. Es importante además incluir otros elementos presentes en la estructura como la diferenciación de la voz del narrador y la de los personajes e insistir en la detección de las secuencias básicas (introductoria, problema y de clausura) en diversos relatos, prestando especial atención para que las historias creadas por los escolares finalicen adecuadamente. Este trabajo es un trabajo previo, pero de gran importancia para la realización posterior de los cómics.

\section{Conocimientos relacionados con el dominio de la estructura}

De la estructura depende que la narración consiga un orden y una coherencia que permitirá al lector encontrar el sentido de la misma. La estructura también se vincula a la dimensión del relato, y en ella se organiza el contenido de la historia a partir de esquemas que son aprendidos a través de las interacciones que el niño mantiene con la narrativa desde la primera infancia.

Los argumentos de las historias infantiles se van haciendo más complejos conforme se avanza en edad. Este hecho se explica porque los niños cada vez son más capaces de interconectar los elementos de la historia en un todo lógico y coherente. Stein (1988) en su investigación sobre narrativas infantiles observó que los niños y niñas de $2^{\circ}$ curso podían ordenar sus historias lógicamente cuando se les presentaban desordenadas. Sin embargo, los alumnos de $5^{\circ}$ curso eran capaces de contar historias en las que incorporaban todos los elementos episódicos en un argumento lógico y coherente, al tiempo que estaban mejor conectadas desde el punto de vista causal. 
La estructura de la historia debe de incluir, tal y como proponen Hudson y Shapiro (1991):

a) Un comienzo formal, en el que se incluye una orientación para presentar a los personajes y el escenario. El comienzo formal incluye una serie de marcas de inicio ("Había una vez...", "En un país muy lejano...") que aluden al género con el que se vincula la historia.

b) El inicio de los acontecimientos que desarrollan las diversas acciones realizadas por los personajes para conseguir sus metas.

c) La aparición del problema que dificulta la consecución de la meta del protagonista.

d) La resolución del problema con el restablecimiento del orden que fue alterado.

e) Un final formal en el que se incluyen una serie de notaciones de clausura de la historia.

La adquisición de habilidades para la elaboración de la estructura de la narración está vinculada a la destreza para construir adecuadamente el argumento con la coherencia necesaria.

En la investigación realizada (Segovia, 2009) sobre el modo en que el alumnado de $3^{\circ}$ ciclo de primaria elabora la temporalidad cuando crea historietas gráficas, observamos que la traslación de las seis secuencias presentes en los argumentos aportados a los escolares (un cuento popular y una sinopsis argumental) se produce parcialmente en los cómics realizados. Comprobamos que en la mayoría de los cómics predomina la representación de la secuencia inicial de apertura y la relacionada con la resolución del problema; en segundo lugar, los escolares atienden a la secuencia de clausura y las secuencias que frecuentemente olvidan representar son las relacionadas con las acciones que anteceden a la aparición del problema y a la escena de clausura de la historia.

No obstante, es importante destacar que sólo en el $10 \%$ de los trabajos analizados cuando el argumento es un cuento popular-, y en un $27,3 \%$, -cuando el argumento procede de una sinopsis- los autores dibujan viñetas correspondientes a todas y cada una de las secuencias. Estas cuestiones nos hacen pensar que la traslación de la estructura interna del relato a un determinado modelo discursivo, requiere de un adiestramiento y conocimiento de la estructura argumental, cuestión que como hemos mencionado debe de estar presente en el currículo de la educación primaria desde los primeros cursos.

Esta capacidad requiere adquirir aprendizajes que permitan: el dominio de habilidades cognitivas para relacionar eventos y personajes en base a relaciones causales y metas vitales; la organización de estos eventos o episodios en una determinada estructura espacio-temporal propia de la narración; y la coordinación del contenido con la estructura narrativa en una trama de ficción. 


\section{Conocimientos relacionados con el dominio de la comunicación lingüística}

Para elaborar narraciones coherentes es necesario que en el plano discursivo se adquieran una serie de destrezas que permitan organizar el discurso de acuerdo con las convenciones del código utilizado y del género con el que se relaciona la narración.

En el caso de las narraciones en las que se utilizan códigos integrados, como es el caso del cómic en el que interaccionan la palabra con el dibujo, el escolar se enfrenta a una síntesis normativa que afecta tanto a la imagen como a los textos escritos.

En el cómic, por un lado, tenemos los textos escritos, que se rigen por las normas del lenguaje escrito; por otro, están las imágenes que tienen como referencia el lenguaje icónico, conformando su propia sintaxis narrativa. Podemos decir que entre la palabra y la imagen se establecen dos tipos de relaciones centrales: la primera de complemento mutuo o integración recíproca -que según los casos repartirá la carga informativa de manera desigual entre la imagen y los textos-, y la otra participando en la construcción del eje temporal del relato, según la cual la palabra -a través de las cartelas y los cartuchos- desempeña diferentes funciones: aclaratoria, explicativa o de enlace entre escenas. Por tanto, ambos lenguajes participan de un código "mestizo" en el que se integran las imágenes, las palabras y los símbolos; todos ellos regidos por una serie de convenciones particulares de este medio expresivo. Es por ello que las competencias lingüísticas necesarias para la elaboración del discurso con este tipo de códigos deban de ser diferentes a las de las narraciones que surgen mediante la escritura o la oralidad.

Además, por las relaciones que establecen sus elementos constituyentes, las modalidades de expresión pueden ser diferentes aunque persigan una misma finalidad. Ante un mismo argumento los escolares pueden crear un cómic con predominio de la iconicidad, mientras que en otro la sustancia narrativa de la trama puede descansar sobre la verbalidad, siendo ambos adecuados desde el punto de vista comunicativo. En el estudio referido (Segovia, 2009), hemos comprobado que en los últimos cursos de la educación primaria, se empiezan a afianzar dos modalidades narrativas, una en la que el dibujo aporta una gran cantidad de información en detrimento de la presencia de textos en las cartelas, y otra en la que el grafismo es mucho más pobre, pero la presencia de textos escritos en globos y cartelas, aporta suficiente información para la adecuada comprensión del argumento.

Desde una perspectiva didáctica, nos interesa destacar que el adecuado conocimiento lingüístico requiere el dominio de los siguientes aspectos:

a) Relacionados con los textos escritos

En el cómic los textos escritos son de gran importancia, ya que de ellos depende la estructuración temporal de la narración y, en gran medida, la complejidad argumental. Las destrezas a desarrollar en este ámbito están relacionadas con la riqueza léxica, con el dominio del tiempo verbal, las partículas conectivas y causales, las estructuras dialogales, etc. Los escolares adquieren estos conocimientos en relación con la competencia en comunicación lingüística realizando tareas y actividades en diversas áreas del currículo, pero especialmente en la de lengua castellana y literatura. 
Entre los conocimientos que deben de adquirir para conseguir la adecuada utilización de los textos escritos en el cómic encontramos los que inciden en el desarrollo de la verbalidad, como son: la diferenciación de las expresiones vinculadas a los personajes que se insertan en los globos, de las que pertenecen al narrador que ocupan el espacio de las cartelas (modalidades de diálogo y voz en el relato); la resolución del desajuste o reiteración informativa entre la imagen y el texto; y las diferentes funciones de los textos en el desarrollo narrativo.

\section{b) Relacionadas con el lenguaje gráfico}

Para la realización de la viñeta, es necesario el dominio de habilidades vinculadas con la expresión gráfica. Éstas forman parte del desarrollo del lenguaje gráfico en la infancia. Sáinz (2006) identifica diferentes modalidades expresivas relacionándolas con las edades de los escolares, y estas evolucionan con el desarrollo cognitivo y perceptivo de los escolares. Los aspectos identificables en cada una de estas modalidades se relacionan, de forma especial, con el dominio de la representación de la figura humana, la representación del espacio, la plasmación de la tridimensionalidad o el uso de la luz y del color.

El desarrollo del lenguaje gráfico del niño se va construyendo progresivamente, dependiendo de aspectos madurativos y culturales. De esta forma se va incorporando una compleja simbología que lo dota de una cualidad común a otros lenguajes, aunque el plástico se caracteriza por la peculiaridad de que sus signos presentan una gran autonomía derivada del alto grado de subjetivismo del estilo gráfico. Pero por otra parte, a medida que el niño se adentra en la cultura, va adquiriendo formas de representación visuales presentes en las artes y en los medios audiovisuales. Por lo tanto, la adquisición de competencias para expresarse mediante el dibujo en el cómic, dependen de factores evolutivos, en la medida que los niños evolucionan desde un modelo preesquemático en el inicio de la escolaridad hasta el del inicio del realismo visual, al final de la etapa primaria (Sáinz, 2006). Esta progresiva complejidad afecta al modo en el que se construye el espacio en la viñeta, afectando a los modos de representación de la figura humana (elaboración del encuadre), la disposición de las figuras y los objetos (representación de la tridimensionalidad y la profundidad de la escena), el uso del color y expresión de la sombra y la luz.

Por otro lado, el cómic como medio de comunicación ha ido elaborando sus propias particularidades expresivas que además se han trasladado a otros medios expresivos como el cine de animación o el anuncio publicitario. Estas formas expresivas son integradas por los niños, de modo que cuando dibujan cómics disponen de un repertorio básico que no dudan en utilizar. Uno de los elementos más claramente identificables en este sentido es el gestuario básico que se utiliza para trasmitir las emociones y estados de ánimo en los personajes, o algunos ideogramas que se utilizan para expresar pensamientos o ideas. Tanto uno como otro son conocidos y utilizados por el escolar sin necesidad de que se 
preste una especial atención para reconocerlos, como si de una "escritura natural" se tratase.

La adquisición de los conocimientos y habilidades propias de la expresión gráfica son importantes para la progresiva adquisición de la competencia cultural y artística, estando relacionados con conocimientos propios del área de expresión artística en su dimensión plástica en el currículo de primaria.

c) Relacionados con el código del cómic

El discurso del cómic se organiza, como hemos expuesto anteriormente, con la integración de textos escritos, imágenes y una serie de convenciones (símbolos $\mathrm{y}$ estructuras de significación particulares). Ese peculiar código ha ido construyéndose a lo largo del tiempo y nos presenta un amplio repertorio de convenciones gráficas mas o menos aceptadas que han sido sistematizadas por diversos dibujantes y semiólogos (Gasca y Gubern, 1999; Eisner, 2003). Para poder expresarse mediante este código es importante que los escolares reconozcan algunas de sus convenciones y las incluyan en sus producciones. La mayoría de las mismas no son extrañas para los escolares pues han estado en contacto con ellas a través de los cómics infantiles, o los dibujos animados. No obstante, es importante dar a conocer de forma sistemática las principales de estas convenciones.

Algunas de ellas, se vinculan con aspectos formales del discurso, como es el caso de la forma, tamaño y organización de las viñetas, el tipo de letras o la adecuada organización de los textos siguiendo las pautas de la línea de indicatividad; mientras que otras se vinculan a aspectos semióticos, como por ejemplo las diferentes formas que adquieren los globos y los deltas de los mismos, los tipos de onomatopeyas o el amplio abanico de ideogramas que son utilizados para aumentar la connotación de la viñeta mediante recursos visuales.

\section{Conocimientos relacionados con el dominio contextual}

Hacen referencia a los conocimientos que posee el escolar sobre la función de la narrativa en función de un contexto cultural determinado, por tanto, se relacionan con la dimensión pragmática del lenguaje y su eficacia comunicativa. La comprensión de este aspecto radica en la capacidad que tiene el narrador para adaptar el discurso a un contexto para conseguir las metas que se proponía con la actividad narrativa. Un ejemplo de lo expuesto se concreta en las modificaciones a que es sometida una narrativa personal según sea relatada en un contexto familiar o en un grupo de amigos.

En el caso de las historietas realizadas por los escolares es importante enfatizar el valor de esta dimensión, pues por diversas causas, su atención se centra prioritariamente en la elaboración de un discurso cuyo principal destinatario son ellos mismos. Esto repercute directamente en el resultado, pues ellos, como autores son capaces de comprender las elipsis que instauran. Sin embargo, un lector diferente tiene difícil la comprensión de la historia, precisamente por esas ausencias. En realidad esta 
es una de las facetas que requieren una atención especial, pues no es fácil la incorporación del lector implícito que debe de llevar todo texto, y más aún en edades tempranas.

\section{Construcción de la temporalidad del cómic}

La elaboración de la temporalidad de la historia es una tarea compleja, pues hemos de tener en cuenta que el hecho narrativo es dependiente de la dimensión temporal para su constitución. Podemos decir que mientras que los hechos vividos pertenecen al momento presente, la narrativización de los mismos requiere de otros momentos, como el pasado o el futuro.

El problema de la relación del tiempo y la narración ha sido estudiado con enorme atención desde la narratología, por lingüistas y filósofos empeñados en diferenciar las múltiples aristas del acto narrativo (Bremond, 1973; Ricoeur, 1987). Sin embargo, nuestra pretensión dista de estos planteamientos, pues nuestro interés está vinculado con el desarrollo de los modelos narrativos visuales en la infancia, por lo que adquiere especial relevancia la cuestión de cómo se manifiesta y conforma la capacidad narrativa en los escolares y cómo aprenden a narrar con imágenes.

La temporalidad está vinculada al orden y sucesividad de los eventos que intervienen en la acción, de tal manera que la historia sería el resultado de una determinada ordenación de los sucesos siguiendo una secuencia natural. Bruner (2006) establece que el orden secuencial es uno de los constituyentes fundamentales de las construcciones narrativas, junto con la agentividad ( tras las acciones siempre hay intenciones), la perspectiva del narrador o la sensibilidad para lo que es canónico y lo que viola la canonicidad.

Por tanto, para trazar la temporalidad en el cómic es necesario que el escolar aprenda a seleccionar y a ordenar las unidades nucleares de la historia. Esta estructuración, que la mayoría de los niños realizan mentalmente, y mantienen en la memoria, será posteriormente discursivizada, trasladándola a las viñetas del cómic.

En la dimensión del relato, la unidad mínima es el acontecimiento o suceso, y como aprecia Muro Munilla (2004), según la importancia funcional que desempeñan los acontecimientos en el desarrollo de la intriga podemos distinguir entre las acciones nucleares, cuya supresión desarticularía la historia, y las adyacentes que, desempeñando una función complementaria, no entran a formar parte de la secuencia medular articulada por el tiempo o la causalidad. Estas unidades mínimas del relato, en los primeros años de la enseñanza primaria, suelen coincidir con cada viñeta, en la que se representa un momento escénico.

Para que el escolar elabore la dimensión temporal del cómic debe atender a dos tareas esenciales. En primer lugar, ha de aprender a plasmar la secuencia de los hechos, con la presencia de los momentos nucleares de la historia a través del argumento; pero, en un segundo momento, en la confección del discurso, mientras dibuja las viñetas, tiene que expresar, mediante los textos escritos y otros recursos gráficos propios del 
lenguaje del cómic, las peculiaridades de la temporalidad de la historia. No participa de la misma temporalidad una viñeta en la que, por ejemplo, aparece un personaje cabalgando, que en otra en la que la misma imagen es acompañada por una cartela en la que se puede leer "después de todo el día cabalgando..."

Este segundo aspecto no está exento de dificultad, pues la imagen, representada a través del dibujo, carece de marcas temporales que le permitan significar el pasado o el futuro. La dimensión icónica de la viñeta apela, en la mayoría de los casos, a un presente exclusivo, y esta acronía ha de ser resuelta a través del código verbal, que así se constituye en verdadero depositario de la dimensión temporal de la historia. Los textos en el cómic, a pesar de que pueden desempeñar diversas funciones, son los encargados de explicitar el discurrir del tiempo en la viñeta y en la página, estableciendo nexos entre las diferentes secuencias, para así salvar las necesarias elipsis narrativas a las que está obligado el discurso por las propias características de la sintaxis del cómic.

Hemos de considerar, por lo tanto, que la temporalidad se basa, por un lado, en la sucesividad de las escenas presentes en las diferentes viñetas, reflejo del desarrollo argumental, y, por otro, en la plasmación de la temporalidad expresada en cada una de ellas.

Los diversos aspectos que han de tenerse en cuenta a la hora de planificar los aprendizajes necesarios para la elaboración de la temporalidad en el cómic son:

a) Selección de las escenas nucleares de la historia. El escolar debe de aprender a seleccionar los momentos significativos de la trama en detrimento de otros cuya importancia es secundaria. Para el desarrollo de esta tarea debe de haber aprendido, a través de sus intercambios culturales con la cultura popular, los elementos que conforman la narración, especialmente los referidos a su carácter dramático y secuencial. Al respecto, Bruner (2006: 60) comenta de las narraciones que "quizá la propiedad más importante sea el hecho de que son inherentemente secuenciales: una narración consta de una secuencia singular de sucesos, estados mentales, acontecimientos en los que participan seres humanos como personajes o actores." Pero para comprender (o elaborar) la trama narrativa hemos de remitirnos a la secuencia de los acontecimientos.

b) Ordenación de las escenas en función de los requerimientos del formato narrativo.

El cómic permite elaborar la estructura temporal de la historia -el tiempo de la representación- utilizando diversos recursos que alteran el orden natural de los sucesos. Por ejemplo, la historia puede empezar y dar un salto al pasado o flash back; o bien plantear secuencias que transcurren paralelamente. Sin embargo en estos primeros años de la escuela primaria, nos interesa consolidar modelos temporales sencillos que reflejen el transcurrir natural de los hechos narrados, evitando la alteración de los mismos.

Como hemos comentado, una de las principales dificultades que nos encontramos es que los escolares elaboran sus historietas sin tener en cuenta al 
destinatario de las mismas, es decir, tienden a identificar al posible lector con el autor que elabora el cómic. Por ello, dejan sin explicitar elementos importantes de la historia, pues los tienen presentes en su memoria. Para reducir este déficit comunicativo que afecta a la dimensión pragmática del discurso es necesario establecer una serie de elementos primordiales que deben de enfatizarse mientras se realiza el trabajo y en la evaluación del mismo.

Centrándonos en el desarrollo de la narrativa visual de los escolares nos interesa trabajar a partir de modelos simplificados, que, al menos, deben incidir en:

- Utilización de marcas temporales ("En tiempos de....", "Érase una vez..", "En el año 2090...”) al inicio del cómic para concretar la temporalidad. La situación de la historia en la secuencia inicial es importante y el escolar debe de aprender a incorporar suficiente información a través de las cartelas en la viñeta inicial.

- $\quad$ Presentación de los personajes principales, así como sus relaciones. Es importante que el niño se acostumbre a aportar suficiente información sobre el protagonista o los protagonistas, pues aunque aparece dibujado, es necesario comprender que la información ha de completarse a partir de los textos de las cartelas o de la inclusión de la misma en los diálogos a través de los globos.

- $\quad$ Aparición del problema que genera la acción dramática. Debemos de insistir en la necesidad que toda historia contenga un problema generador de la acción, y conforme trabajamos en los cursos medios y superiores debemos de preocuparnos para que el escolar lo presente de forma adecuada y explícita.

- $\quad$ Resolución del problema. Si el problema es el elemento primordial que desencadena la acción dramática, su resolución es un elemento indispensable para la adecuada construcción del argumento, por ello es un aspecto al que hay que prestar atención prioritaria.

- Clausura de la narración. Es otro de los elementos en los que debemos de insistir, pues en muchas ocasiones, bien por incapacidad, motivación o cansancio, el escolar suele abandonar la clausura del relato, cuando esta es una de las secuencias fundamentales para mantener la estructura del mismo.

c) Adecuación del lenguaje gráfico y el escrito a la sintaxis del cómic para expresar el tiempo.

La expresión mediante el lenguaje verboicónico requiere de la adecuada utilización de normas sintácticas apropiadas, pues la dimensión temporal de la historia se presenta de forma primordial a través de la viñeta a través de los textos escritos. Pero por otra parte, también se plasma la temporalidad de la historia en la secuencia de viñetas representadas, pues cada una de ellas se 
relaciona con la que le antecede y le sigue trazando la línea argumental. Esta secuencia de momentos es la concreción formal del tiempo representado, a pesar de que hay momentos del relato que quedan elípticos y forman parte del tiempo de la representación. Pero mientras las escenas nucleares estén presentes, las elipsis no deben de dificultar la comprensión de la historia.

Puesto que en los niveles educativos de primaria no priorizaremos el uso de recursos temporales sofisticados que afectan a modalidades del montaje, para la plasmación de la temporalidad en la viñeta nos centraremos en:

- La adecuada utilización de las cartelas en la viñeta para la inclusión de marcas temporales, de forma que las transiciones temporales queden suficientemente explícitas. Especialmente importante es la presencia de la voz del narrador, puesto que en el caso de los escolares de primaria, el autor asume siempre una posición heterodiegética, es decir, contando la historia desde fuera del relato, en tercera persona $\mathrm{y}$ adoptando, por tanto, una actitud omnisciente. A través de los textos que se inscriben en la cartela el autor ofrece determinadas informaciones indispensables para situar la acción en las coordenadas espacio-temporales, y esto es importante realizarlo en las viñetas iniciales.

- La colocación y utilización de los globos para los diálogos de los personajes siguiendo determinadas convenciones para su intervención en la acción. Desde el punto de vista de la temporalidad, la viñeta comporta una contradicción, pues la imagen representa un instante de la acción, mientras que los textos que la acompañan dotan a la escena de una mayor o menor temporalidad. La dimensión de ese momento se relaciona con los diálogos de los personajes y en cierto sentido condiciona la percepción subjetiva que tiene el lector, pues tiene que dedicar un tiempo para su lectura. Por ello, la introducción de una mayor o menor cantidad de globos y cartelas en la viñeta se convierte en elemento determinante del ritmo narrativo. En los primeros cursos de primaria, los escolares eluden incorporar textos escritos en la viñeta, pues mediante el lenguaje gráfico se expresan con mucha más facilidad que con el escrito. El proceso de incorporación de los textos de apoyo y los diálogos de los personajes requiere de un tratamiento específico y continuado no exento de dificultad. Es importante que el escolar diferencie claramente las aportaciones del narrador de las de los personajes y aprenda a organizar correctamente los diversos textos en el espacio de la viñeta respetando las convenciones propias de la lectura.

- El conocimiento y uso del repertorio de convenciones gráficas que se utilizan para plasmar el transcurso del tiempo (relojes, calendarios, líneas cinéticas,...) 
- La utilización de modelos sencillos de montaje de las viñetas para la secuenciación correcta del argumento a través de la puesta en página. Ya hemos comentado que el modelo de montaje adecuado para estas edades debe de ser sencillo y con un número limitado de viñetas.

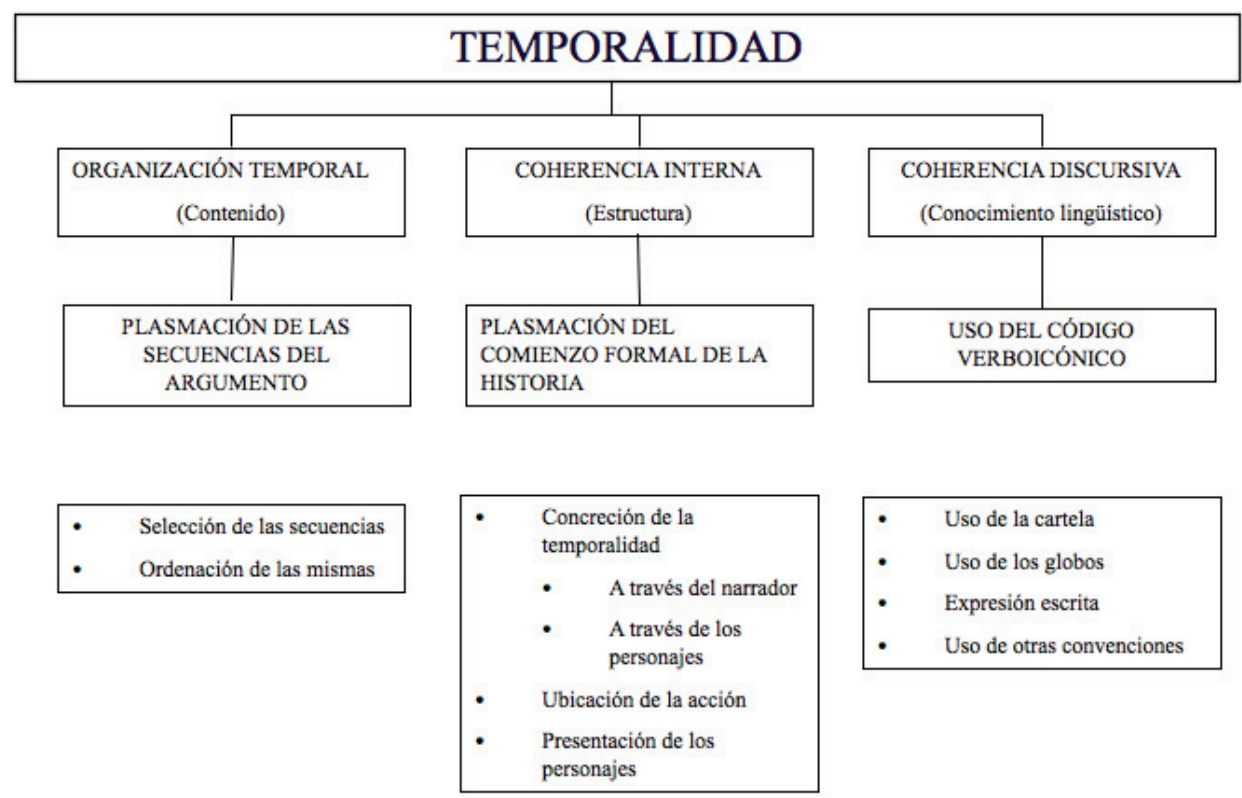

Ilustración 1. Dimensiones de la temporalidad en el cómic

\section{La creación del espacio en los cómics infantiles}

En el cómic, como en cualquier narración, tiempo y espacio se configuran como elementos indisociables de la historia. Como hemos mencionado anteriormente, el argumento estructura la temporalidad a través de la sucesión de unos acontecimientos que se actualizan en diversos espacios o escenarios.

La dimensión icónica del cómic provoca que la plasmación de los momentos principales de la trama se concreten en las diversas viñetas a través del dibujo de la escena, de forma que el tratamiento del espacio, indispensable para el desarrollo de la acción argumental, queda vinculado con la representación gráfica. En este sentido, podemos decir que el espacio anticipa al tiempo, pues debe apoyarse en él, o dicho de 
otro modo: en el discurso del cómic la temporalidad necesita de la espacialidad de la viñeta para poder realizarse y así construir la narración. La viñeta, por tanto, se considera como elemento estructural básico, y según Gubern (1972) se convierte "en la representación pictográfica del mínimo espacio y/o tiempo significativo, que constituye la unidad de montaje de un cómic".

Por otro lado, la condición verboicónica del discurso, hace que la constitución y percepción del espacio atienda, sobre todo, al sentido de la vista, expresándose en un primer momento en el encuadre de cada viñeta, y completándose después con la composición de la totalidad de la página.

En nuestro caso, atender a la dimensión espacial de cómics realizados por niños nos obliga a considerar la evolución que se produce en la adquisición del lenguaje gráfico,

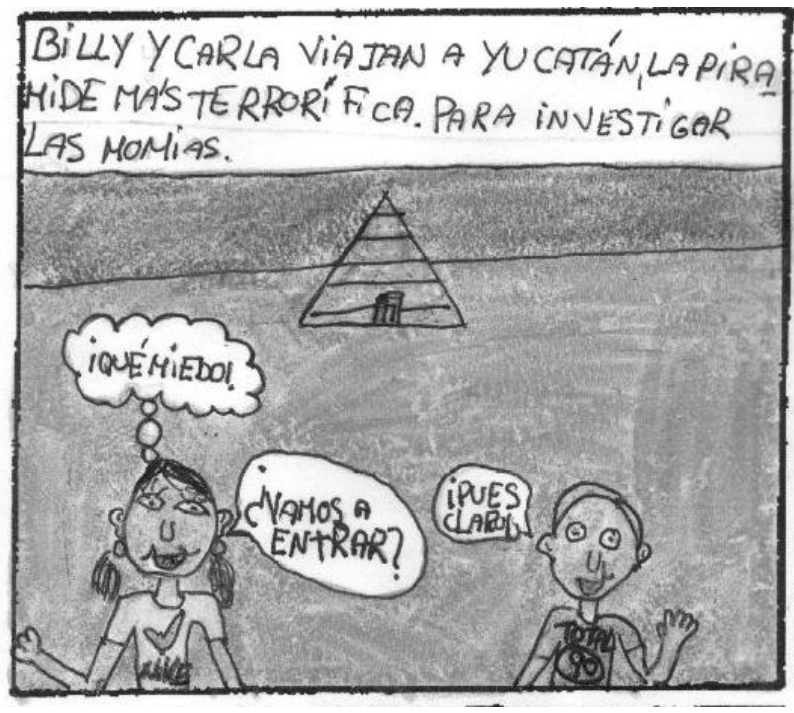

Ilustración 2. Viñeta realizada por alumna de $6^{\circ}$ de E. Primaria

pues de él depende principalmente la representación del espacio. Es necesario tener presente cómo y cuando se producen cambios significativos en el desarrollo de la expresión gráfica durante la infancia pues afectan, entre otras cosas, a la plasmación del espacio, tal y como demuestran los diversos estudios realizados sobre la evolución del dibujo en la infancia (Sáinz, 2006). Por ello, si la capacidad para estructurar la temporalidad de la historia se vincula con competencias narrativas, la dimensión espacial en el cómic depende, en gran medida, del dominio del lenguaje gráfico, que es instrumento indispensable para dibujar la viñeta, y como hemos mencionado anteriormente, las propiedades del lenguaje gráfico del escolar están relacionadas con aspectos madurativos y culturales.

\section{La viñeta como espacio escénico}

En la viñeta podemos distinguir dos tipos de espacio que coinciden. Uno es el espacio que denominamos topológico, entendiéndolo como la superficie ocupada por la viñeta sobre la superficie del papel. Los límites de este espacio los establece la línea de demarcación, que como veremos más adelante, puede adquirir un importante valor semántico. El segundo tipo de espacio es el representado mediante la figuración. Ambos espacios están íntimamente relacionados, pues el segundo (espacio narrativo) 
existe en función de la actuación que la operación del encuadre hace sobre el primero (espacio real). Mientras que en otros lenguajes que utilizan la imagen, como la fotografía o el cine, las relaciones que se establecen entre ambos espacios son relativamente estrictas, ya que están sujetas a determinados modelos de formatos, en el cómic se caracterizan por su diversidad, y el espacio real de la viñeta puede adquirir dimensiones diversas y formatos variados (tamaño variable, formatos rectangulares, cuadrados, circulares,...) Aunque el encuadre es el elemento básico de creación de significados, ya que articula el denominado espacio diegético, es decir aquel en el que se produce narración y por tanto, muestra y narra al tiempo, podemos apreciar diferencias en la manera en la que se crean los mecanismos de significación dependiendo de que sea un lenguaje que utiliza la imagen fija, (la fotografía o la pintura), la imagen en movimiento (el cine) o la imagen fija articulada (el cómic y la fotonovela).

Quizá la manera de identificar con más facilidad las características del espacio narrativo de la viñeta sea comparándola con la fotografía y con el plano cinematográfico. La viñeta coincide con la fotografía en que pretende ser la representación de un momento de la acción en un espacio. Mediante el encuadre el autor crea dos espacios distintos que se complementan: el "on" y el "off". El primero integra a todos los elementos incluidos en el encuadre, mientras que el segundo alude a todos los demás que han sido excluidos de él.

Pero el espacio "on" de la fotografía y el de la viñeta son diferentes desde el punto de vista del significado y desde luego de la figuración. En la fotografía lo podemos definir como de carácter centrípeto y excluyente, pues lo que no ha sido representado dentro del encuadre deja de existir en el campo de la significación. Si en el encuadre aparece, por ejemplo, un niño montado en una bicicleta cruzando por una calle, es solo lo que aparece retratado en el encuadre lo que adquiere significación. Podría ocurrir que un coche lo persigue, o quizá un perro, pero si no están presentes dentro de los límites del encuadre no tienen ni tendrán carta de naturaleza. Sin embargo, en la viñeta o en el plano cinematográfico ocurre de diferente manera. El carácter narrativo y la sucesividad actúan semánticamente de otra manera. El encuadre lo podríamos denominar como centrífugo e integrador del espacio "off”, ya que ese espacio que en la viñeta ha quedado momentáneamente excluido puede ser activado en el siguiente cuadro convirtiéndose, entonces en espacio "on". Siguiendo con el ejemplo anterior podríamos comprobar que en el siguiente encuadre vemos a un perro que corre en la misma dirección que lo hacía el niño de la bicicleta. En el cine y en menor medida en el cómic, el encuadre se convierte en el marco de algo que anticipa y espera a lo que ha de venir.

Will Eisner (1996: 41), autor y creador de obras significativas como la serie Spirit o New York City comenta: "la creación de la viñeta empieza con la selección de los elementos necesarios de la narración, la elección de una perspectiva desde donde pueda verlos el lector, y la determinación de la parte de cada símbolo o elemento que va confinado en la viñeta. Así, en la realización de cada viñeta no sólo se respeta el dibujo y la composición, sino también su consecuencia narrativa". 
De lo expuesto podemos destacar, en primer lugar, la importancia de la funcionalidad narrativa que aporta la viñeta como un espacio, similar a un escenario, en el que los personajes y sus intervenciones sustentan parte de la trama de la historia. Pero la creación de este espacio escénico se hace a partir de la combinación de microunidades significativas (Gubern, 1972) que quedan delimitadas por el contorno de la viñeta que actúa como un elemento más de significación dependiendo de la forma que adquiera (cuestión imposible de realizar con la fotografía o cine). Sin embargo, no todos los elementos que aparecen dentro de la viñeta detentan el mismo rango de importancia.

\section{La disposición de los personajes}

La disposición de los personajes y de los objetos en el espacio de la viñeta se establece en torno a dos ejes que construyen el espacio virtual. Uno representa la horizontalidad y verticalidad a través de la organización izquierda-derecha y arribaabajo, y otro la profundidad a través del eje delante-atrás. El primero, en el cómic, está mediatizado por la convención que rige el orden de la lectura denominada línea de indicatividad. Ello supone que el dibujante, a la hora de organizar a los personajes como si se tratase de un escenario de teatro, ha de tener en cuenta la disposición de las alocuciones verbales, ya que en nuestra cultura predomina el orden de lectura izquierda-derecha y arriba-abajo. A veces, esta circunstancia complica de forma importante la composición de la viñeta, ya que por su tendencia a la elipsis narrativa, en la viñeta se han de incorporar una importante información verbal que sostenga la trama de la historia y la disposición de los globos determina el lugar ocupado por los personajes.

El segundo eje, el que configura la profundidad, se construye mediante procedimientos propios del lenguaje plástico abundante en la ilustración o en la pintura. Los recursos principales son la utilización de las diferentes perspectivas, el ocultamiento de las figuras, los efectos de trazo y coloreado y los efectos de iluminación. A diferencia de lo que ocurre con el cine los dibujantes de cómics siempre han podido experimentar una gran diversidad de recursos para la representación de este campo en profundidad llegando a crear diferentes espacios escénicos en una misma viñeta como los dibujados por Alex Raymond en Flash Gordon o W. McCay en Little Nemo. En estos casos nos encontramos composiciones en las que se superponen diferentes escenas dentro del espacio virtual de la viñeta organizadas en torno al eje de la profundidad y provocando una dimensión temporal añadida. Sin embargo otros autores (Schulz, Herriman, Quino o Calpurnio) prescinden de estas posibilidades expresivas y plantean escenas en las que la profundidad carece de interés, pues en su narrativa priorizan la información verbal sobre la icónica.

\section{La construcción del encuadre}

El marco de la viñeta actúa como un receptáculo delimitador del espacio representado, un escenario en el que aparecen los personajes, los objetos y los textos. El escolar selecciona y presenta los momentos del argumento que considera más 
relevantes y los dibuja en el encuadre. Por esta razón, para poder concretar el espacio donde transcurren los acontecimientos, el niño necesita de sus conocimientos y habilidades gráficas y trazar un escenario que se presenta limitado por el formato y la dimensión de la viñeta. En este sentido, como refiere Sáinz (2006), resulta fácil apreciar diferencias sustanciales derivadas de la capacidad expresiva que el niño tiene en diferentes edades para representar el espacio y el profesorado debe de ser consciente de ello.

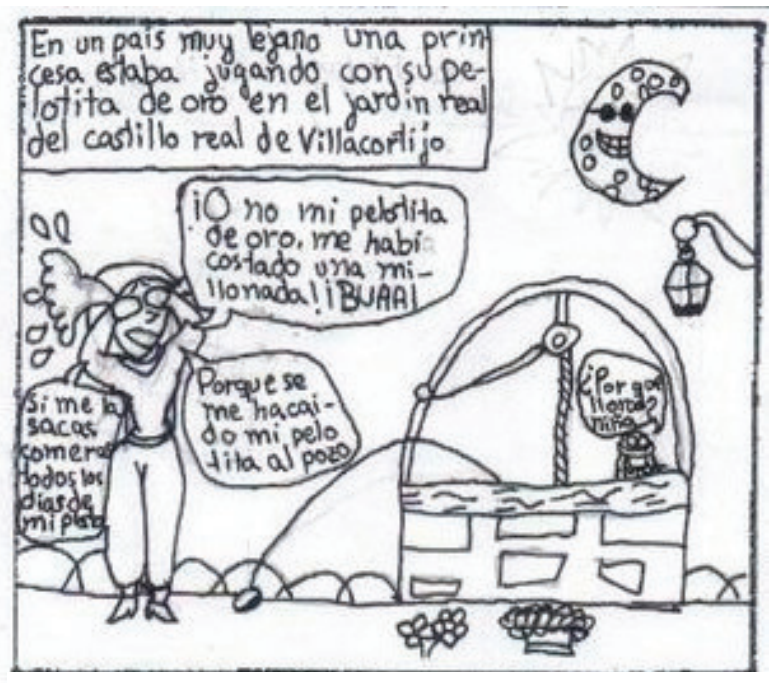

La representación de una acción en el espacio de la viñeta requiere que el autor o autora haya adquirido una serie de habilidades que le permitan la construcción del encuadre, pues no podemos obviar que la operación de representación espacial a través del encuadre está fundamentado en convenciones culturales que forman parte del alfabeto visual. Este es uno de los fundamentos para poder elaborar la narrativa visual, pues implica el dominio de la escala, el punto de vista y el formato de la viñeta.

Ilustración 3. Viñeta de alumna de $5^{\circ}$ E. Primaria

Para el tratamiento pedagógico de este aspecto de la narrativa del cómic, debemos prestar atención a una serie de cuestiones que inciden en la elaboración de la viñeta como espacio narrativo, tales como:

a) La organización del escenario, pues el autor debe trasladar a un espacio de dos dimensiones, como es la viñeta, la tridimensionalidad propia de la realidad. La plasmación de la profundidad en un espacio topológico bidimensional supone un conflicto que el escolar soluciona de diversas formas dependiendo de su edad cronológica y la riqueza de las experiencias plásticas que ha podido tener. La representación de la perspectiva acontece en los últimos cursos de la enseñanza primaria, cuando el niño se adentra en la etapa del realismo visual (Sáinz, 2006).

b) La disposición de los personajes y los objetos en el espacio representado. Esta operación se asemeja a una puesta en escena de los personajes que intervienen en la acción y está mediatizada por el dominio del dibujo y la plasmación de la profundidad de la escena. La disposición de los personajes en la viñeta es subsidiaria del modelo de representación del espacio del escolar. Dependiendo de las habilidades gráficas del escolar, detectamos una progresión (Segovia, 2009) que va haciéndose cada vez más compleja siguiendo los patrones: a) modelo en el 
que las figuras no se vinculan a una organización espacial concreta; b) los personajes se colocan sobre la base de la viñeta; c) se dibujan sobre la línea horizontal que representa el suelo; d) se distribuyen sobre el eje delante-atrás, siendo este último modelo en el que se empiezan a trazar elementos de propios de la perspectiva, tales como la disminución del tamaño de las figuras en razón de su lejanía de la base de la viñeta o la ocultación parcial de las mismas por la interposición de otras figuras más cercanas al hipotético observador, como podemos observar en la ilustración 2.

c) La intervención del encuadre como elemento narrativo, lo que conlleva incorporar a la composición de la viñeta la semantización del marco que la delimita, teniendo en cuenta la relación entre espacio "on" y "off". Al utilizar el marco de la viñeta como límite del encuadre, el niño adjetiva la escena representada mediante una serie de procedimientos como son: la segmentación de la figura a partir de la escala de planos, la adopción de un determinado punto de vista, así como la atribución de valor narrativo al espacio exterior al encuadre. Consideramos tres aspectos determinantes en la forma en la que los niños de la escuela primaria entienden el encuadre a la hora de dibujar la viñeta: a) la capacidad para incorporar la fragmentación de la figura, pues en los primeros cursos se tiende a presentarla entera, en plano general; b) la presencia del fuera de campo como elemento indicador del poder de significación del encuadre, y c) el uso de un repertorio variado de planos en la realización de la historieta. Algunos escolares, a partir de $3^{\circ}$ y $4^{\circ}$ curso empiezan a incluir en sus viñetas representaciones de la figura en diferentes escalas, lo cual es indicativo de la puesta en práctica de una incipiente narrativa visual, sin embargo otros que no adquieren la madurez y destrezas necesarias con el dibujo presentan sus trabajos utilizando únicamente planos generales en cada una de las viñetas, lo cual no es óbice para que la expresión mediante los textos no sea adecuada.

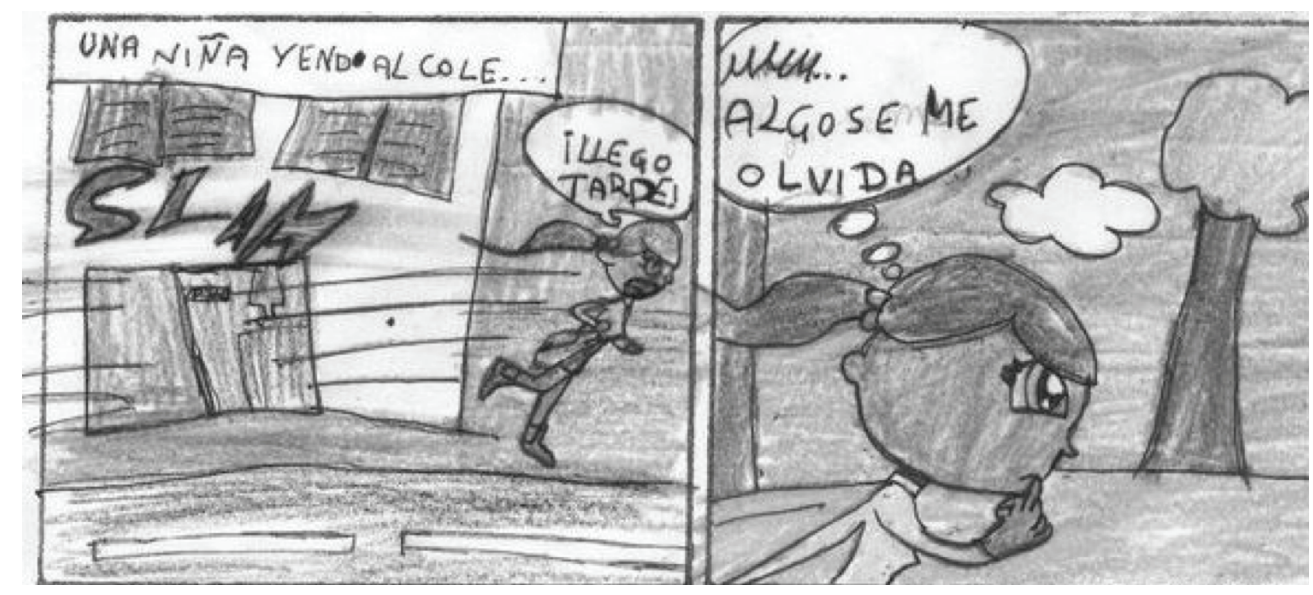




\section{Ilustración 4: Uso intencionado del encuadre en viñetas de alumna de $6^{\circ}$ curso}

d) La incorporación de normas sintácticas para favorecer la lectura de los elementos verbales y los icónicos de la viñeta, como por ejemplo la línea de indicatividad o la colocación de los textos en lugares adecuados. La organización de los diferentes elementos constitutivos de la viñeta supone la progresiva incorporación de elementos que inciden en la riqueza visual de la composición. Desde el uso de un gestuario básico para connotar los estados de ánimo de los personajes, hasta la utilización de líneas cinéticas para indicar las trayectorias de los objetos o la inclusión de los ideogramas y las onomatopeyas, son variados los recursos que van enriqueciendo y mejorando la calidad discursiva de los cómics de los escolares.

e) El montaje o relación que se establece entre las viñetas de la página, que con toda seguridad reproducirá modelos sencillos, en los que predomina la discontinuidad total, es decir, cada viñeta dará cuenta de un escenario diferente.

En resumen, la construcción del espacio en las narraciones visuales de los escolares debe de contemplar la existencia de diversos modelos compositivos y expresivos para la representación espacial, y éstos aparecerán en función de las destrezas adquiridas por los escolares según su edad y experiencia con el dibujo; unos más sencillos, dominados por la bidimensionalidad, y otros más complejos, en los que será posible apreciar la tridimensionalidad, mediante la articulación del eje delante-atrás, el volumen de los objetos y las relaciones de tamaño, distancia y desplazamiento de las figuras.

El profesorado deberá adecuar sus propuestas en función de los niveles educativos, teniendo en cuenta las destrezas gráficas conseguidas por su alumnado. Por ejemplo, en los primeros cursos las viñetas han de tener un formato y unas dimensiones apropiadas que permitan la correcta expresión de las imágenes y los textos, por lo que en una página debemos incluir cuatro viñetas. Sin embargo, en los últimos cursos ya podemos abordar composiciones de páginas de mayor complejidad, con un mayor número de viñetas y modificando el formato y tamaño de las mismas. 


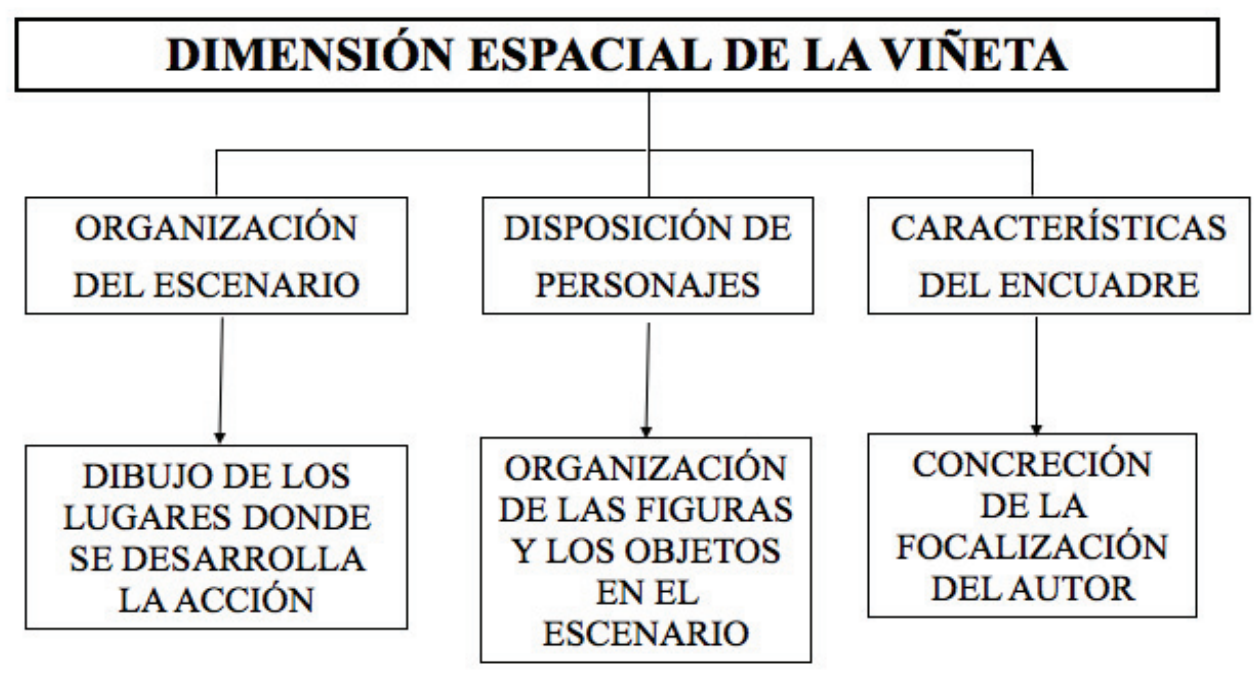

Ilustración 5. Elementos constitutivos de la espacialidad

\section{Consideraciones finales}

El aprendizaje de la competencia narrativa en la educación primaria implica trabajar en diversos ámbitos. Uno relacionado con la capacidad de crear historias, pues la narración, como se enfatiza desde la psicología sociohistórica [Bruner (2004), Santamaría y Martínez (2005), Smorti (2001),], forma parte de la relación del sujeto con la cultura y ha de ser aprendida explícitamente en contextos generadores de cultura, especialmente en la escuela. Otro de los ámbitos es el relacionado con los fundamentos de la educación mediática (Aparici, 1996; Gutiérrez y Tyner, 2012; Segovia, 2010; UNESCO, 2008), pues es necesario adquirir conocimientos y destrezas que permitan al alumnado expresarse con códigos en los que se integran las imágenes y las palabras, y esta cuestión depende de una adecuada alfabetización en el lenguaje icónico.

Desde nuestra perspectiva, las acciones destinadas al desarrollo de la competencia narrativa se pueden adquirir a través del cómic, debiendo de integrar tres dimensiones: los aprendizajes para la creación del contenido argumental; los aprendizajes para la adecuación del discurso a los requerimientos del lenguaje verboicónico y los aprendizajes relacionados con el cómic y los nuevos medios de comunicación. 
a) Los aspectos relacionados con el contenido descansan en el dominio de la organización temporal de la historia, junto con aspectos estructurales. Todos ellos confluyen en la elaboración del argumento, es decir, tienen como finalidad consolidar aprendizajes que permitan al niño expresar la sucesión de hechos o vivencias siguiendo un "orden natural temporal" de los acontecimientos.

b) Actividades favorecedoras de la adecuación del discurso

El escolar tiene que aprender a adecuar el discurso al proceso de comunicación para que la historia consiga el mayor grado posible de eficacia comunicativa. En el cómic nos encontramos con una peculiar dimensión discursiva que se construye con diversidad de signos, por lo que el niño debe de alternar dos tipos de códigos: uno basado en el alfabeto y otro en la imagen.

El tratamiento didáctico de cómo aprende el escolar a expresarse con este tipo de código requiere, por tanto, de una serie de intervenciones destinadas a: la consecución de las habilidades necesarias para expresarse mediante el lenguaje gráfico; el dominio de aspectos relacionados con la expresión escrita para la elaboración de los textos; el conocimiento de convenciones propias del cómic, como las que rigen para el uso de las onomatopeyas, los diversos tipos de globos, etc.; la organización de la página mediante el montaje; y la construcción del espacio en función del encuadre y punto de vista.

En el caso del cómic, es preciso atender a ciertas cuestiones que influyen directamente en la incorporación de la palabra en la viñeta. Quizá la más destacable es la habilidad que el escolar debe adquirir para expresar el argumento distribuyendo su contenido mediante el estilo indirecto, propio de la cartela, y el directo, con los globos de los personajes. Esta dualidad, que implica tener presente diferentes voces en la narración - el narrador y los personajes- presenta ciertas dificultades entre los escolares. Igualmente, es importante trabajar en la dimensión retórica del discurso, intentando la reflexión individual o colectiva de los niños sobre sus propias composiciones, unas veces para evitar las abundantes elipsis informativas producidas por la ausencia de textos escritos, y otras para corregir la redundancia que se produce al presentar la misma información mediante imágenes y palabras.

El conocimiento de las convenciones propias del cómic es uno de los aspectos que más deben de interesarnos, pues a lo largo de sus más de cien años de historia, este medio de expresión ha ido construyendo un código en el que se integran diversidad de elementos. Unos relacionados con las relaciones que se establecen entre las imágenes y las palabras -por ejemplo, la función fática que se incluye a partir de la adjetivación icónica de las onomatopeyas-, y otros singulares que caracterizan a diferentes signos o estilemas (Gasca y Gubern, 1999) -como es el caso del amplísimo repertorio de ideogramas-.

El montaje de la página, contemplada como una unidad narrativa, nos ofrece una excelente estrategia para construir el tiempo de la narración. En un principio, debemos preocuparnos en que el niño adquiera destrezas que le permitan trasladar las diversas secuencias primordiales del argumento sobre un número determinado de 
viñetas, distribuyéndolas con eficacia y equilibrio. Para ello, será necesario aprender a realizar procesos de revisión y actualización previos a la concreción de la historia, como pueden ser la guionización del argumento con modelos sencillos, como por ejemplo, poner un título para cada una de las escenas y adjudicarle una viñeta. La finalidad de este tipo de actividades debe de ser doble: por un lado, aprender a organizar con corrección las secuencias del relato, y por otro, representarlas respetando los principales elementos estructurales de la narración.

c) Aspectos relacionados con el cómic y los nuevos medios de comunicación

La dimensión educativa del trabajo con los medios, dentro de una perspectiva sociocrítica, no puede obviar la reflexión sobre aspectos que caracterizan al cómic como producto de la industria del entretenimiento. En los últimos cursos de primaria, pueden abordarse una serie de temáticas propias del cómic o comunes con otros medios de comunicación, como: el estudio de estereotipos en los personajes, la industria del cómic, formas de participación como audiencia de los nuevos medios, etc.

En definitiva, se trata de articular las propuestas educativas, complementando la dimensión textual con los elementos contextuales, para iniciar a los chicos y chicas en la apropiación de los productos de los medios de comunicación. Este tipo de actividades pueden, además, trasladarse a otros productos de los media como son los juegos de ordenador, las series de animación o los programas televisivos.

\section{Referencias bibliográficas}

APARICI, R. (coord.) (1996). La revolución de los medios audiovisuales: educación y nuevas tecnologías. Madrid: De la Torre.

BREMOND, C. (1973). La logique du recit. París: Du Seuil.

BRUNER, J. S. (2004). Realidad mental y mundos posibles: los actos de la imaginación que dan sentido a la experiencia. Barcelona: Gedisa.

BRUNER, J. S. (2006). Actos de significado: Más allá de la revolución cognitiva, Madrid: Alianza Editorial.

COMUNICAR (Ed.) (2012). Alfabetización mediática en contextos múltiples (Vol. 38). Huelva: Grupo Comunicar.

EISNER, W. (1996). El cómic y el arte secuencial. Barcelona: Norma.

EISNER, W. (2003). La narración gráfica. Barcelona: Norma.

FERRÉS, J. (2007). La competencia en comunicación audiovisual. Comunicar, 29, 100-107.

GASCA, L. y GUBERN, R. (1999). El discurso del cómic. Madrid: Cátedra.

GUBERN, R. (1972). El lenguaje de los cómics. Barcelona: Península. 
GUTIÉRREZ, A., y TYNER, K. (2012). Educación para los medios, alfabetización mediática y competencia digital. Revista Comunicar, 38, 31-39.

HUDSON, J. Y SHAPIRO, L. (1991). From knowing to telling: The development of children's scripts, stories and personal narratives. En A. McCabe \& C. Peterson (Eds.), The developing narrative structure (pp. 89-136). Hillsdale, New Jersey: Lawrence Erlbaum Associated.

LANKSHEAR, C. Y KNOBEL, M. (2008). Nuevos alfabetismos: su práctica cotidiana y el aprendizaje en el aula. Madrid: Morata.

LONSDALE, M. Y McCURRY, D. (2004). Literacy in the new millenium. En N. C. f. V. E. R. (NCVER) (Eds.) Available from

http://www.ncver.edu.au/publications/1490.html

MATEOS BLANCO, T., Y NÚÑEZ CUBERO, L. (2011). Narrativa y educación: indagar la experiencia escolar a través de los relatos. Revista de la Educación, 23, 2, 111-128.

MURO MUNILLA, M. A. (2004). Análisis e interpretación del cómic. Ensayo de metodología semiótica. Logroño: Universidad de la Rioja. Servicio de Publicaciones.

RICOEUR, P. (1987). Tiempo y narración. Vol.2 Configuración del tiempo en el relato de ficción. Madrid: Ediciones Cristiandad.

SÁINZ, A. (2006). El arte infantil: conocer al niño a través de sus dibujos. Madrid: Eneida.

SANTAMARÍA, A. Y MARTÍNEZ RODRÍGUEZ, M. A. (2005). La construcción de significados en el marco de la Psicología Cultural: el Pensamiento Narrativo. En: Cubero, M. y Ramírez, J.D. (Eds.). Vygotski en la psicología contemporánea (pp. 167-193). Buenos Aires: Miñón y Dávila.

SEGOVIA, B. (2009). Análisis de las construcciones narrativas del espacio y del tiempo en los cómics de los escolares de tercer ciclo de Enseñanza Primaria. Córdoba: Servicio de Publicaciones de la UCO.

SEGOVIA, B. (2010). Desarrollo de la narrativa visual de los escolares con el cómic. Revista Iberoamericana de Educación, 51/5, 11.

SMORTI, A. (2001). El pensamiento narrativo: construcción de historias y desarrollo del conocimiento social. Sevilla: Mergablum.

STEIN, N. L. (1988). The development of children's storytelling skill. En: M.B. Frankin \& S. Barten (Eds.) Child language: A book of readings (pp. 282-297). New York, N.Y.: Oxford University Press.

UNESCO (2008). Teacher Training Curricula for Media and information Literacy. Report of the International Expert Group Meeting. Paris: International UNESCO. (http://portal.unesco.org/ci/fr/ fi les/ - 275 08/12212271723Teacher- 
Training_Curriculum_for_ MI L_final_report.doc/Teacher-Training\%2BCurri

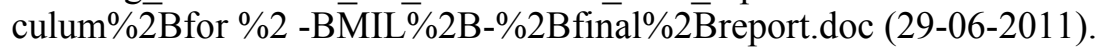

WHITE, H. (1980): The value of narrativity in the representation of reality. En: Mittchel, W. J. T. (Ed.) On narative (pp. 5-27). Chicago-London: The University Chicago Press.

\section{Correspondencia con el autor}

Dr. Blas Segovia Aguilar

Dpto. de Educación

Universidad de Córdoba (España)

E-mail: bsegovia@uco.es 